\title{
Sarcopenia is a prognostic factor for overall survival in elderly patients with head-and-neck cancer
}

\author{
N. Chargi ${ }^{1}$ S. I. Bril ${ }^{1,2} \cdot$ M. H. Emmelot-Vonk ${ }^{3} \cdot$ R. de Bree ${ }^{1,4}$
}

Received: 18 January 2019 / Accepted: 22 February 2019 / Published online: 4 March 2019

(c) The Author(s) 2019

\begin{abstract}
Objectives Sarcopenia is known as a geriatric syndrome associated with increased disability and decreased survival in elderly patients. In oncological patients, pretreatment low skeletal muscle mass (SMM), sometimes referred to as sarcopenia, is an emerging negative prognostic factor. Commonly, only SMM is assessed in cancer patients. Sarcopenia is defined as the combination of low SMM and low muscle function (MF). We investigated the relation between SMM, MF, sarcopenia (SMM and MF combined), and overall survival (OS) in a group of elderly patients with head-and-neck squamous cell carcinoma (HNSCC).

Patients and methods A retrospective study in elderly HNSCC patients treated between 2015 and 2018 was performed. The prognostic value of SMM and MF seperately, and sarcopenia was investigated.

Results Eighty-five patients were included of whom $48.2 \%$ had sarcopenia. The median OS was significantly worse for patients treated with curative intent with sarcopenia (12.07 months; IQR 3.64-21.82) compared to patients without sarcopenia (13.60 months; IQR 5.98-27.00) (HR 2.80; 95\% CI 1.14-6.88; $p=0.03$ ). SMM and MF seperately were not significant predictors of OS.

Conclusion Sarcopenia is associated with impaired OS in elderly HNSCC patients. Sarcopenia, defined as the combination of low SMM and low MF, appears to be a better predictor of OS than low SMM or low MF separately.
\end{abstract}

Keywords Body composition $\cdot$ Muscle function $\cdot$ Head-and-neck neoplasms $\cdot$ Survival $\cdot$ Sarcopenia

R. de Bree

r.debree@umcutrecht.nl

N. Chargi

n.chargi@umcutrecht.nl

S. I. Bril

s.i.bril@umcutrecht.nl

M. H. Emmelot-Vonk

m.h.emmelotvonk@umcutrecht.nl

1 Department of Head and Neck Surgical Oncology, UMC Utrecht Cancer Center, University Medical Center Utrecht, Heidelberglaan 100, 3584, CX, Utrecht, The Netherlands

2 Department of Medical Oncology, UMC Utrecht Cancer Center, University Medical Center Utrecht, Heidelberglaan 100, 3584, CX, Utrecht, The Netherlands

3 Department of Geriatrics, University Medical Center Utrecht, Heidelberglaan 100, 3584, CX, Utrecht, The Netherlands

4 Department of Head and Neck Surgical Oncology, University Medical Center Utrecht, House Postal Number Q.05.4.300, PO BOX 85500, 3508, GA, Utrecht, The Netherlands

\author{
Abbreviations \\ SMM Skeletal muscle mass \\ HNC Head-and-neck cancer \\ C3 Third cervical vertebra \\ L3 Third lumbar vertebra \\ CSMA Cross-sectional muscle area \\ HU Hounsfield unit \\ Lumbar SMI Lumbar skeletal muscle index
}

\section{Introduction}

Research into the field of body composition and specifically low skeletal muscle mass (SMM), sometimes also referred to as sarcopenia, has increasingly gained interest over the last decade in the field of oncology. In geriatrics, sarcopenia is known as an age-related syndrome with a multifactorial etiology, characterized by generalized loss of SMM and loss of muscle strength [1].

Risk factors for the presence of sarcopenia are malnutrition, immobilization, and illness. Sarcopenia is a risk factor 
for various adverse outcomes including physical disability, decreased quality of life, and ultimately death [1]. In human aging, muscle wasting is an imminent process. It is estimated that the prevalence of sarcopenia in the general population is $5-13 \%$ for people aged $60-70$ years, and up to $50 \%$ for those aged 80 years or above [2]. Independent of age, sarcopenia is impaired in various diseases due to inflammation, malnutrition, and immobilization. Cachexia is a complex metabolic syndrome in which inflammation is the key feature and weight loss ( $\geq 5 \%$ of body weight during the past 12 months) is the key diagnostic criterium. Cachexia can be an underlying condition in patients with sarcopenia [3].

The majority of research within the oncological community has defined sarcopenia as radiologically assessed low SMM and/or low skeletal muscle quality. Previous research in elderly people showed that the correlation between SMM and muscle strength is moderate-to-weak, and the relationship between muscle strength and SMM is not linear [4, 5]. For this reason, the European working group on sarcopenia in older people (EWGSOP) recommended diagnosing sarcopenia based on the presence of both low SMM and low muscle function (MF; strength or performance) [1].

Within the field of oncology, radiologically assessed low SMM appears to be a negative predictive and prognostic factor for various outcomes including disease progression and survival in a variety of cancer types [6]. For example, radiologically assessed low SMM is associated with chemotherapy dose-limiting toxicity in patients with head-andneck cancer [7], breast cancer [8], and renal cell carcinoma [9]; increased incidence of postoperative complications in patients with head-and-neck cancer [10,11], esophageal squamous cell carcinoma [12] and colorectal cancer [13]; and decreased survival in patients with head-and-neck cancer [11, 14], colorectal cancer [15], and pancreatic adenocarcinoma [16].

In the majority of studies on the effect of sarcopenia on survival of cancer patients, and in all studies regarding headand-neck cancer patients, only radiologically assessed low SMM was used to define sarcopenia. There are very few studies available in cancer patients that assess the prognostic value of sarcopenia as defined by the combination of low SMM and low MF. One study performed with gastric cancer patients who underwent gastrectomy showed that patients with sarcopenia, as defined by the combination of low SMM and low MF, showed a significantly higher complication rate compared to patients without sarcopenia [17]. In headand-neck cancer, no studies are available on the relationship between sarcopenia, as defined by the combination of low SMM and low MF, and adverse outcomes. The aim of this study is to explore the relationship between sarcopenia and overall survival in elderly patients with head-and-neck cancer.

\section{Materials and methods}

\section{Patients and study design}

This study was designed as a single-center retrospective study. We reviewed elderly patients ( $\geq 70$-years old) with pathologically proven head-and-neck squamous cell carcinoma (HNSCC) who had a geriatric assessment during their diagnostic workup between April 2015 and February 2018. In our center, elderly HNSCC patients are offered geriatric assessment, but patients may refuse. Histologic tumor types other than squamous cell carcinoma were excluded. The design of this retrospective study was approved by the Medical Ethical Research Committee of our center (approval ID 17-365/C).

Factors with known or suspected relation with HNSCC treatment outcomes and with sarcopenia were collected: age, sex, body mass index (BMI), weight loss in the past 6 months, risk of malnutrition assessed with the malnutrition universal screening tool (MUST), smoking status, alcohol use, comorbidity expressed as a Charlson Comorbidity Index (CCI) score, tumor type (primary, second primary or recurrence), tumor site, human papillomavirus (HPV) status (for oropharyngeal cancer), tumor-node-metastasis (TNM) stage, hematological and biochemical markers at diagnosis, including hemoglobin $(\mathrm{Hb})$, leukocytes, C-reactive protein (CRP), creatinine and albumin, and treatment intention.

\section{Definition of sarcopenia}

Sarcopenia was defined as the combination of low SMM and low MF, as determined by muscle strength or physical performance measurements [1].

\section{Skeletal muscle mass}

Skeletal muscle mass was measured as cross-sectional muscle area (CSMA) on pretreatment CT or MRI imaging of the head-and-neck area at the level of the third cervical vertebrae (C3). The axial slide of the imaging which showed both transverse processes and the entire vertebral arc was selected for the segmentation of muscle tissue. For CT imaging, muscle area was defined as the pixel area between the radiodensity range of -29 and +150 Hounsfield units (HU), which is specific for muscle tissue [18]. For MRI, muscle area was manually segmented, and fatty tissue was manually excluded.

Segmentation of muscle tissue was manually performed using the commercially available software package SliceOmatic (Tomovision, Canada). Cross-sectional muscle area 
Table 1 Patient characteristics

\begin{tabular}{|c|c|c|}
\hline Characteristics & Mean (SD) & Frequencies $n,(\%)$ \\
\hline \multicolumn{3}{|l|}{ Sex } \\
\hline Female & & $47(55.3)$ \\
\hline Male & & $38(44.7)$ \\
\hline Age (years) & $81.5(6.5)$ & \\
\hline BMI $\left(\mathrm{kg} / \mathrm{m}^{2}\right)$ & $26.9(4.8)$ & \\
\hline \multicolumn{3}{|l|}{ Smoking status } \\
\hline Never & & $30(35.3)$ \\
\hline Former & & $46(54.1)$ \\
\hline Current & & $9(10.6)$ \\
\hline \multicolumn{3}{|l|}{ Pack-years } \\
\hline $1-20$ & & $8(9.4)$ \\
\hline $21-40$ & & $10(11.8)$ \\
\hline $41-60$ & & $4(4.7)$ \\
\hline$\geq 61$ & & $7(8.2)$ \\
\hline \multicolumn{3}{|l|}{ Alcohol use } \\
\hline Never & & $28(32.9)$ \\
\hline Former & & $8(9.4)$ \\
\hline Current & & $49(57.6)$ \\
\hline \multicolumn{3}{|c|}{ Alcohol intake (units/day) } \\
\hline$<2$ & & $37(43.5)$ \\
\hline $2-4$ & & $12(14.1)$ \\
\hline$\geq 5$ & & - \\
\hline \multicolumn{3}{|c|}{ Charlson comorbidity index } \\
\hline Mild (0-3) & & $4(4.7)$ \\
\hline Moderate (4-5) & & $10(11.8)$ \\
\hline Severe $(\geq 6)$ & & $71(83.5)$ \\
\hline \multicolumn{3}{|c|}{ Weight loss in the past 6 months } \\
\hline None & & $56(65.9)$ \\
\hline$<10 \%$ & & $23(27.1)$ \\
\hline$\geq 10 \%$ & & $6(7.1)$ \\
\hline \multicolumn{3}{|l|}{ MUST score } \\
\hline$<2$ & & $66(77.6)$ \\
\hline$\geq 2$ & & $19(22.4)$ \\
\hline \multicolumn{3}{|l|}{ TNM stage } \\
\hline I & & $11(12.9)$ \\
\hline II & & $19(22.4)$ \\
\hline III & & $16(18.8)$ \\
\hline IV & & $39(45.9)$ \\
\hline \multicolumn{3}{|l|}{ Tumor type } \\
\hline Primary & & $65(76.5)$ \\
\hline Second primary & & $6(7.1)$ \\
\hline Recurrent & & $14(16.5)$ \\
\hline \multicolumn{3}{|l|}{ Tumor site } \\
\hline Oral cavity & & $52(61.2)$ \\
\hline Nasopharynx & & $2(2.4)$ \\
\hline Oropharynx* & & $5(5.9)$ \\
\hline Hypopharynx & & $3(3.5)$ \\
\hline Larynx & & $8(9.4)$ \\
\hline Skin & & $12(14.1)$ \\
\hline Salivary glands & & $1(1.2)$ \\
\hline Paranasal sinuses & & $2(2.4)$ \\
\hline
\end{tabular}

Table 1 (continued)

\begin{tabular}{|c|c|c|}
\hline Characteristics & Mean (SD) & Frequencies $n,(\%)$ \\
\hline \multicolumn{3}{|c|}{ Treatment intention } \\
\hline Curative & & $71(83.5)$ \\
\hline Palliative & & $14(16.5)$ \\
\hline
\end{tabular}

*Four patients had HPV-negative oropharyngeal cancer; one patient had missing data on HPV status

at the level of C3 was converted to CSMA at the level of L3 using a previously published formula [19]. The lumbar skeletal muscle index (SMI) was calculated by correcting SMM at the level of L3 for height. Patients had a low SMI if this value was below $43.2 \mathrm{~cm}^{2} / \mathrm{m}^{2}$; this cut-off value was established in a separate cohort of head-and-neck cancer patients [7].

\section{Muscle strength}

Isometric handgrip strength (HGS) is strongly related with overall muscle strength [20]. Handgrip strength was measured using a Jamar hydraulic handheld dynamometer according to the recommendations of the American society of hand therapist's (ASHT) and expressed in kilograms (kg). Patients were asked to squeeze maximally with each hand. The average score of the left and right hands was used for analysis. Patients had low HGS if the HGS was below $30 \mathrm{~kg}$ (men) or below $20 \mathrm{~kg}$ (women) [1].

\section{Muscle performance}

The 4-m gait speed is a reflection of individual's lower limb muscle function. It is a widely accepted way to assess muscle performance [21]. Gait speed was measured as the average speed during a 4-m walking test. The time measured to complete a 4-m walk was measured. Patients had low muscle performance if the 4-m gait speed was below $0.8 \mathrm{~m} / \mathrm{s}$ [1].

\section{Statistical analysis}

Data analyses were performed using IBM SPSS statistics 25. Descriptive statistics for continuous variables with a normal distribution were presented as mean with standard deviation (SD). Variables with a skewed distribution were presented as median with interquartile range (IQR). Categorical variables were presented as frequencies and percentages. Likelihood ratio (LR) Chi-square statistics were used for analyzing associations of the percentages of each categorical variable with the presence or absence of sarcopenia. Independent sample $t$ tests were used for comparing the means of the hematological and biochemical markers with the presence or absence of sarcopenia. 
Table 2 General characteristics of the study patients by the presence of sarcopenia

\begin{tabular}{|c|c|c|c|c|c|c|}
\hline & \multicolumn{2}{|c|}{ Sarcopenia } & \multicolumn{2}{|c|}{$\begin{array}{l}\text { Without sarco- } \\
\text { penia }\end{array}$} & \multirow[t]{2}{*}{$\begin{array}{l}\text { Likelihood ratio } \\
\text { (LR) }\end{array}$} & \multirow[t]{2}{*}{$p$ value } \\
\hline & $n$ & $(\%)$ & $n$ & $(\%)$ & & \\
\hline Age (years) & & & & & 8.82 & 0.08 \\
\hline $70-75$ & 7 & 43.8 & 9 & 56.3 & & \\
\hline $76-80$ & 8 & 32 & 17 & 68 & & \\
\hline $81-85$ & 12 & 48 & 13 & 52 & & \\
\hline $86-90$ & 5 & 62.5 & 3 & 37.5 & & \\
\hline$>90$ & 9 & 81.8 & 2 & 18.2 & & \\
\hline BMI $\left(\mathrm{kg} / \mathrm{m}^{2}\right)$ & & & & & 7.70 & 0.07 \\
\hline$\leq 18.5$ & 3 & 100 & - & - & & \\
\hline $18.5-25$ & 17 & 56.7 & 13 & 43.3 & & \\
\hline $25-30$ & 14 & 46.7 & 16 & 53.5 & & \\
\hline$\geq 30$ & 7 & 31.8 & 15 & 68.2 & & \\
\hline MUST score & & & & & 0.19 & 0.80 \\
\hline$<2$ & 31 & 47.0 & 35 & 53.0 & & \\
\hline$\geq 2$ & 10 & 52.6 & 9 & 47.4 & & \\
\hline Smoker & & & & & 8.37 & $0.02 *$ \\
\hline No & 18 & 60 & 12 & 40 & & \\
\hline Yes & 7 & 77.8 & 2 & 22.2 & & \\
\hline Former & 16 & 34.8 & 30 & 65.3 & & \\
\hline Pack-years & & & & & 2.26 & 0.55 \\
\hline $1-20$ & 5 & 62.5 & 3 & 37.5 & & \\
\hline $21-40$ & 3 & 30 & 7 & 70 & & \\
\hline $41-60$ & 2 & 50 & 2 & 50 & & \\
\hline$\geq 61$ & 4 & 57.1 & 3 & 42.9 & & \\
\hline Alcohol use & & & & & 4.57 & 0.23 \\
\hline No & 17 & 60.7 & 11 & 39.3 & & \\
\hline Former & 4 & 50 & 4 & 50 & & \\
\hline Current & & & & & & \\
\hline$\leq 2$ units/day & 17 & 45.9 & 20 & 54.1 & & \\
\hline$\geq 2$ units/day & 3 & 25 & 9 & 75 & & \\
\hline CCI & & & & & 4.00 & 0.07 \\
\hline$\leq 6$ & 11 & 34.3 & 21 & 65.6 & & \\
\hline$>6$ & 30 & 56.6 & 23 & 43.4 & & \\
\hline TNM stage & & & & & 0.94 & 0.84 \\
\hline I & 5 & 45.4 & 6 & 54.5 & & \\
\hline II & 8 & 42.1 & 11 & 57.9 & & \\
\hline III & 7 & 43.8 & 9 & 56.3 & & \\
\hline IV & 21 & 53.8 & 18 & 46.2 & & \\
\hline Treatment intention & & & & & 1.74 & 0.25 \\
\hline Curative & 32 & 45.1 & 39 & 54.9 & & \\
\hline Palliative & 9 & 64.3 & 5 & 35.7 & & \\
\hline Radiotherapy & & & & & 0.45 & 0.87 \\
\hline No & 24 & 49 & 25 & 51 & & \\
\hline Yes, primary & 8 & 42.1 & 11 & 57.9 & & \\
\hline Yes, adjuvant & 9 & 52.9 & 8 & 47.1 & & \\
\hline Chemotherapy (not applicable) & - & & - & & - & - \\
\hline Surgery & & & & & 0.47 & 0.62 \\
\hline No & 12 & 54.5 & 10 & 45.5 & & \\
\hline Yes & 29 & 46 & 34 & 54 & & \\
\hline Synchronous tumor & & & & & 1.82 & 0.36 \\
\hline
\end{tabular}


Table 2 (continued)

\begin{tabular}{|c|c|c|c|c|c|c|}
\hline & \multicolumn{2}{|c|}{ Sarcopenia } & \multicolumn{2}{|c|}{$\begin{array}{l}\text { Without sarco- } \\
\text { penia }\end{array}$} & \multirow[t]{2}{*}{$\begin{array}{l}\text { Likelihood ratio } \\
\text { (LR) }\end{array}$} & \multirow[t]{2}{*}{$p$ value } \\
\hline & $n$ & $(\%)$ & $n$ & $(\%)$ & & \\
\hline No & 40 & 50 & 40 & 50 & & \\
\hline Yes & 1 & 20 & 4 & 80 & & \\
\hline Metachronous tumor & & & & & 0.95 & 0.62 \\
\hline No & 40 & 49.4 & 41 & 50.6 & & \\
\hline Yes & 1 & 25 & 3 & 75 & & \\
\hline Recurrence & & & & & 0.20 & 0.65 \\
\hline No & 35 & 47.3 & 39 & 52.7 & & \\
\hline Yes & 6 & 54.5 & 5 & 45.5 & & \\
\hline Dead & & & & & 5.17 & $0.03 *$ \\
\hline No & 20 & 38.5 & 32 & 61.5 & & \\
\hline Yes & 21 & 63.6 & 12 & 36.4 & & \\
\hline SMI & & & & & 24.54 & $<0.01 * *$ \\
\hline Low & 41 & 59.4 & 28 & 40.6 & & \\
\hline High & - & & 16 & 100 & & \\
\hline HGS & & & & & 24.57 & $<0.01 * *$ \\
\hline Low & 35 & 70 & 15 & 30 & & \\
\hline High & 6 & 17.1 & 29 & 82.9 & & \\
\hline Gait speed & & & & & 19.14 & $<0.01 * *$ \\
\hline Low & 37 & 63.8 & 21 & 36.2 & & \\
\hline High & 4 & 14.8 & 23 & 85.2 & & \\
\hline
\end{tabular}

*Correlation is significant at the 0.05 level (two-tailed)

$* *$ Correlation is significant at the 0.01 level (two-tailed)

Table 3 Hematological and biochemical markers of the study patients by the presence or absence of sarcopenia

\begin{tabular}{lcccc}
\hline & $\begin{array}{l}\text { Sarcopenia } \\
\text { (mean, SD) }\end{array}$ & $\begin{array}{l}\text { Without sarcopenia } \\
\text { (mean, SD) }\end{array}$ & Mean difference (SD) & $95 \%$ CI \\
\hline $\mathrm{Hb}(\mathrm{mmol} / \mathrm{L})$ & $8.09(1.06)$ & $8.67(1.12)$ & $-0.58(0.26)$ & -1.10 to -0.05 \\
$\mathrm{CRP}(\mathrm{mg} / \mathrm{L})$ & $9.93(15.10)$ & $8.12(11.86)$ & $1.81(3.38)$ & -4.93 to 8.56 \\
Leukocytes $\left(\times 10^{\wedge} 9 / \mathrm{L}\right)$ & $10.78(8.24)$ & $8.15(2.45)$ & $2.63(1.44)$ & -0.25 to 5.51 \\
Albumin $(\mathrm{g} / \mathrm{L})$ & $39.56(2.28)$ & $40.98(2.53)$ & $-1.42(1.14)$ & -3.83 to 0.99 \\
Creatinine $(\mu \mathrm{mol} / \mathrm{L})$ & $87.55(30.95)$ & $95.38(51.06)$ & $-7.84(10.43)$ & -28.65 to 12.98 \\
\hline
\end{tabular}

*Correlation is significant at the 0.05 level (2-tailed)

Pearson's correlation was used to assess the correlation between SMM, MF parameters, age, and BMI. Only patients with curative treatment intent were selected for overall survival analysis. Survival was visualized using Kaplan-Meier survival curves and number at risk tables. We defined overall survival as the time elapsed between the date of histologic diagnosis and death or date of last follow-up, whichever occurred first. We calculated the 3-year overall survival rate for patients with sarcopenia and without sarcopenia, Wilcoxon test was used for analyzing the statistical significance of the difference in 3-year overall survival rate. A cox proportional hazard regression model was used for univariate and multivariate analyses of survival. Covariates used in the multivariate analysis were selected based on clinical significance or selected based on statistical significance $(p<0.05)$ in univariate cox regression analysis. Statistical significance was evaluated at the 0.05 level using two-sided tests.

\section{Results}

\section{Patient characteristics}

Descriptive data are described in Table 1. A total of 85 patients were included with a mean age of 81.5 years 
Table 4 Pearson correlation analysis for variables associated with sarcopenia

\begin{tabular}{llllll}
\hline Measures & SMI & HGS & Gait speed & Age & BMI \\
\hline SMI & - & 0.16 & -0.15 & $-0.37^{*}$ & $-0.46^{*}$ \\
HGS & 0.16 & - & $-0.39 *$ & $0.28^{*}$ & -0.04 \\
Gait speed & -0.15 & $-0.39^{*}$ & - & - & 0.05 \\
Age & $-0.37^{*}$ & $-0.46^{*}$ & $0.28^{* *}$ & -0.02 & -0.02 \\
BMI & $0.49^{*}$ & -0.04 & 0.05 & - \\
\hline
\end{tabular}

*Correlation is significant at the 0.01 level (two-tailed)

**Correlation is significant at the 0.05 level (two-tailed)

(SD 6.5). The majority of patients were female (55.3\%) with a mean BMI of $26.9 \mathrm{~kg} / \mathrm{m}^{2}$ (SD 4.8). Most patients were former smokers $(54.1 \%)$ with mean pack-years of 21-40 years. Most patients had multiple comorbidities, as represented by a high Charlson Comorbidity Index score (CCI). Most patients underwent treatment with curative intent $(83.5 \%)$. The median follow-up time was 11.14 months (IQR 3.64-21.83 months); 33 patients (38.8\%) died during the study period.

Of the 85 included patients; 69 patients $(81.2 \%)$ had low SMI, 50 patients $(58.8 \%)$ had low HGS, and 58 patients (68.2\%) had low gait speed. Forty-one patients (48.2\%) were classified as sarcopenic; of these patients, 31 patients (75.6\%) had low SMI in combination with low HGS and low gait speed, six patients (14.6\%) had low SMI in combination with low gait speed and normal HGS, and four patients (9.8\%) had low SMI in combination with low HGS and normal gait speed.

Tables 2 and 3 show the general characteristics and the hematological and biochemical markers of the included patients according to the presence or absence of sarcopenia. Patients with sarcopenia were most likely to smoke
Fig. 1 Kaplan-Meier overall survival curves and number at risk table for patients with low SMI and high SMI showed no statistically significant difference (Log-rank chi-square 1.14; $p=0.29)$

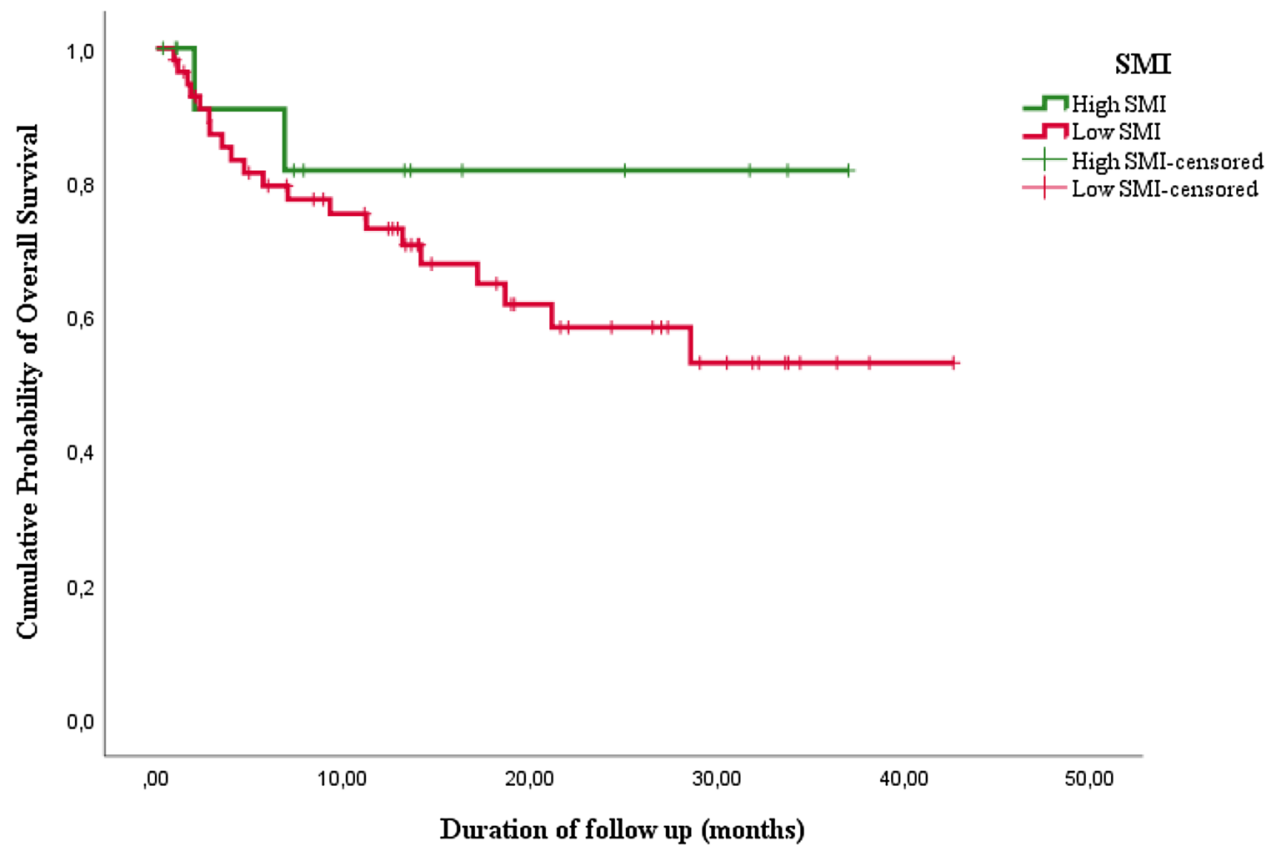

\begin{tabular}{|l|l|l|l|l|}
\hline & $T=0$ & $T=12$ & $T=24$ & $T=36$ \\
\hline Low SMI & 57 & 33 & 15 & 3 \\
\hline High SMI & 14 & 7 & 4 & 1 \\
\hline
\end{tabular}


Fig. 2 Kaplan-Meier overall survival curves and number at risk table for patients with low handgrip strength (HGS) and high HGS showed no statistically significant difference (Log-rank chi-square 1.35; $p=0.25)$

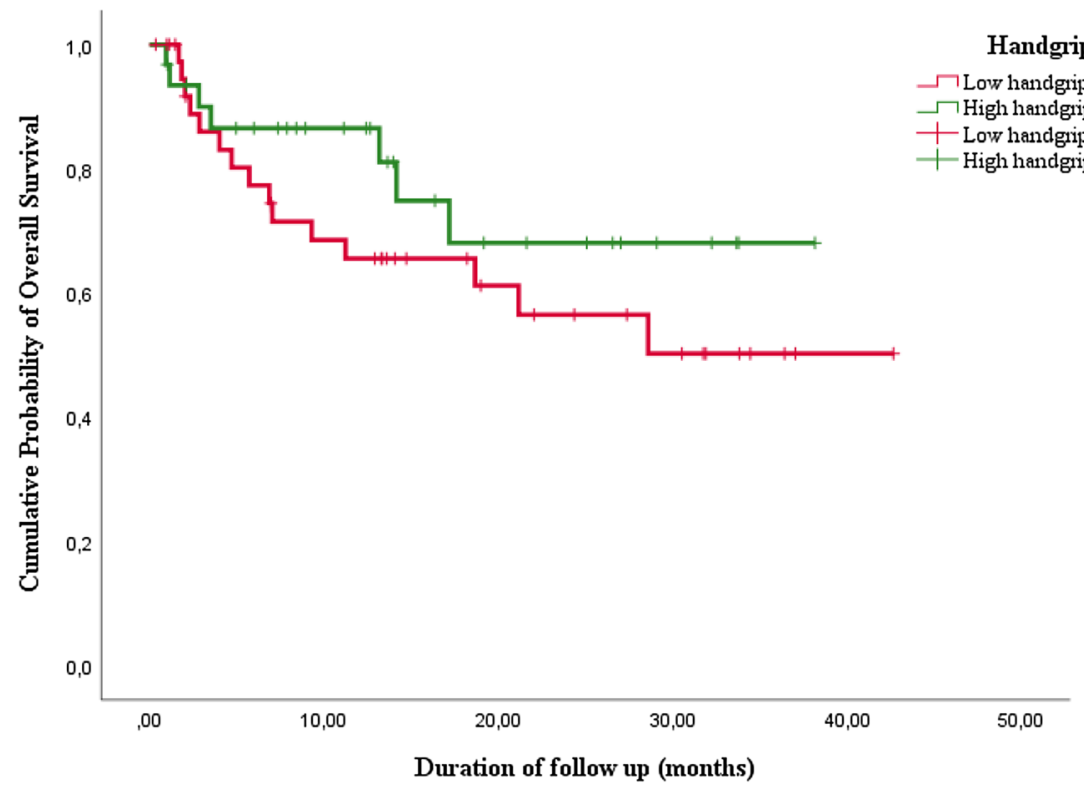

\begin{tabular}{|l|l|l|l|l|}
\hline & $T=0$ & $T=12$ & $T=24$ & $T=36$ \\
\hline Low HGS & 40 & 22 & 11 & 3 \\
\hline High HGS & 31 & 18 & 8 & 1 \\
\hline
\end{tabular}

(77.8\% versus $22.2 \%$; LR $8.37, p=0.02$ ), to have lower mean hemoglobin levels at diagnosis $[8.09 \mathrm{mmol} / \mathrm{L}$ (SD 1.06) versus $8.67 \mathrm{mmol} / \mathrm{L}$ (SD 1.12); $p=0.03$ ] and to die (63.6\% versus $36.4 \%$; LR 5.17, $p<0.01$ ).

\section{Correlation analysis}

Results from the correlation analyses are shown in Table 4. Significant low-to-moderately strong correlation coefficients are seen for SMI and BMI $(r=0.49)$, SMI and age $(r=-0.37)$, HGS and age $(r=-0.46)$, gait speed and age $(r=0.28)$, and for gait speed and HGS $(r=-0.39)$.

\section{Survival analysis}

Results from the Kaplan-Meier survival analysis are shown in Figs. 1, 2, 3, and 4. As shown in Figs. 1, 2, and 3, the median overall survival appears to be shorter for patients treated with curative intent with high SMI compared with patients with low SMI (10.58 versus 13.34 months; log-rank test $p=0.29$ ), but this difference was not statistically significant. The differences in OS between patients with low HGS compared with patients with high HGS (13.31 versus 13.17 months; log-rank test $p=0.25$ ) and for patients with low gait speed compared with patients with high gait speed (11.94 versus 16.36 months; log-rank test $p=0.16$ ) were not significant either. The median overall survival was significantly shorter for patients treated with curative intent with sarcopenia compared to patients without sarcopenia (12.07 versus 13.60 months; log-rank test $p=0.02$ ), as is illustrated in Fig. 4. The overall 3-year survival rate was significantly shorter for patients treated with curative intent with sarcopenia compared to patients without sarcopenia (39\% versus 75\%; Wilcoxon Statistic 4.48, $p=0.03$ ).

Results from the univariate and multivariate cox regression analysis for overall survival are shown in Table 5. Sarcopenia (HR 2.80; 95\% CI 1.14-6.88; $p=0.03$ ) and TNM stage IV (HR 15.64; 95\% CI 1.99-122.88; $p=0.01$ ) were significant prognostic factors for overall survival in univariate cox regression analysis. In multivariate cox regression analysis, model 1 shows that sarcopenia (HR 2.66; 95\% CI1.07-6.58; $p=0.04$ ) remained a significant prognostic factor for overall survival independent of age, $\mathrm{Hb}$ level, BMI, MUST score, and comorbidity. However, sarcopenia did not remain a significant prognostic factor when TNM stage was included (model 2). TNM stage IV was a significant prognostic factor for overall survival in multivariate cox regression analysis (HR 15.64; 95\% CI 1.99-122.88; $p=0.01$ ).

A subgroup analysis according to TNM stage was performed, of which the results are shown in Table 6 . 
Fig. 3 Kaplan-Meier overall survival curves and number at risk table for patients with low gait speed and high gait speed showed no statistically significant difference (Log-rank chi-square $1.95 ; p=0.16$ )

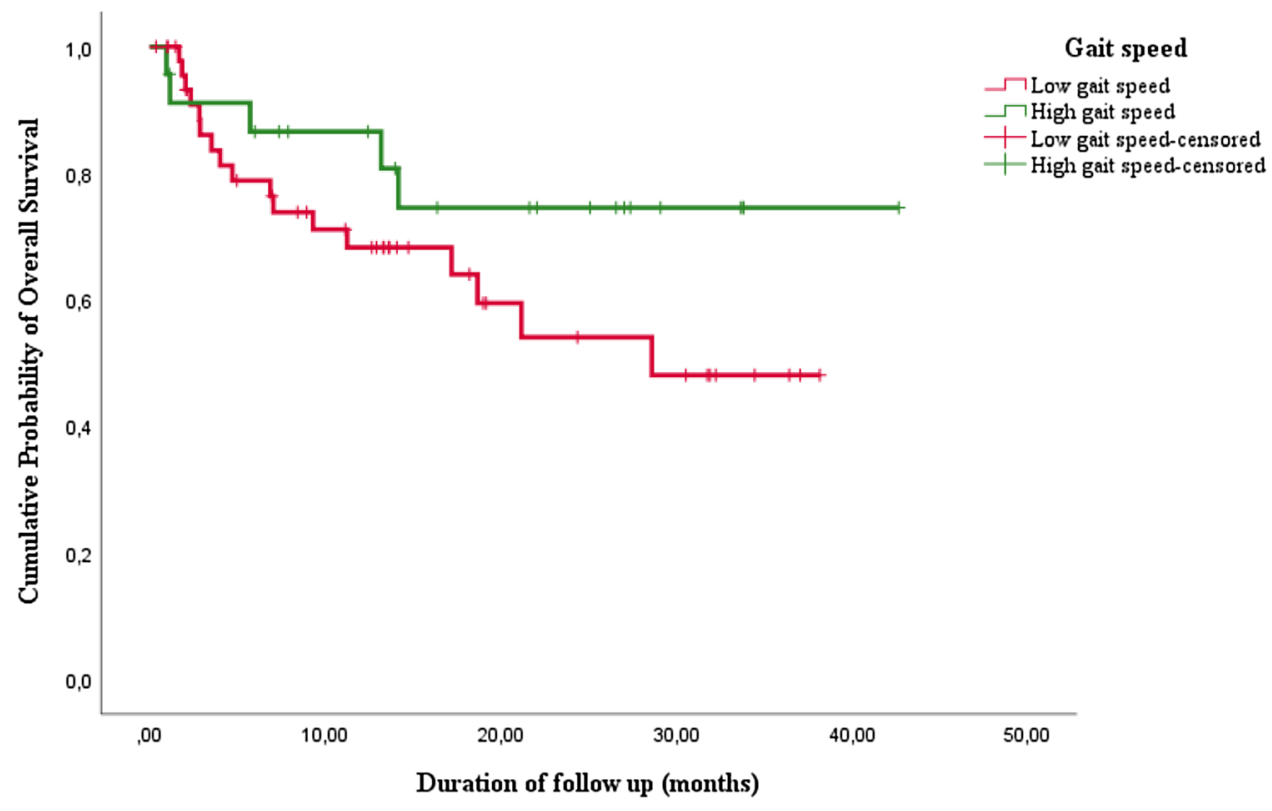

\begin{tabular}{|l|l|l|l|l|}
\hline & $T=0$ & $T=12$ & $T=24$ & $T=36$ \\
\hline Low gait speed & 48 & 24 & 10 & 3 \\
\hline High gait speed & 23 & 16 & 9 & 1 \\
\hline
\end{tabular}

Sarcopenia was a statistically significant prognostic factor for overall survival in patients with TNM stage I-III (HR 9.19; 95\% CI 1.07-78.74; $p=0.04$ ). However, sarcopenia was not a statistically significant prognostic factor for overall survival in patients with TNM stage IV (HR 0.90; 95\% $0.32-2.55 ; p=0.85)$.

\section{Discussion}

Sarcopenia is a common and highly prevalent clinical problem in the elderly patient. Literature showed that sarcopenia is associated with several negative outcomes; however, literature mainly focuses on radiologically assessed low SMM rather than the combination of SMM and MF [6-16]. In addition, no studies report on the impact of sarcopenia on survival in the elderly head-and-neck cancer patient. Identification of the impact of low SMM and low MF on prognosis in the elderly head-and-neck cancer patient will stimulate the development of novel interventions to gain SMM and MF which may improve the prognosis of these patients. Regardless of the success of an intervention, information on prognosis can be used for patient counseling and treatment decision making.
In this study, we included 85 patients of whom 41 patients (48.2\%) were classified as sarcopenic. This number is in accordance with recent medical literature which estimated the prevalence of sarcopenia in elderly patients diagnosed with different types of cancer between 14 and 78.7\% [22]. The prevalence estimates of sarcopenia in the elderly noncancer patients are lower, ranging between 5 and $50 \%$. Sarcopenia is prevailing in elderly cancer patients because of the frequent weight loss caused by low food intake, increased catabolic pathways, increased inflammation, increased lipolysis, and increased proteolysis associated with both old age and malignancy [22].

This study shows that SMM, muscle strength, and physical functioning separately had no significant prognostic value for overall survival. A combination of muscle mass and muscle strength or muscle performance did show a significant prognostic value for overall survival in elderly patients with head-and-neck cancer. This is in accordance with previous studies in other tumor types, which have demonstrated that not only SMM but also MF is related with several health outcomes [22-24]. Previous studies in patients with esophageal cancer did not show a significant prognostic value of sarcopenia on overall survival; however, sarcopenia was defined as low radiologically assessed SMM only rather 
Fig. 4 Kaplan-Meier overall survival curves and number at risk table for patients with and without sarcopenia showed statistically significant difference (Log-rank chi-square 5.50; $p=0.02$ )

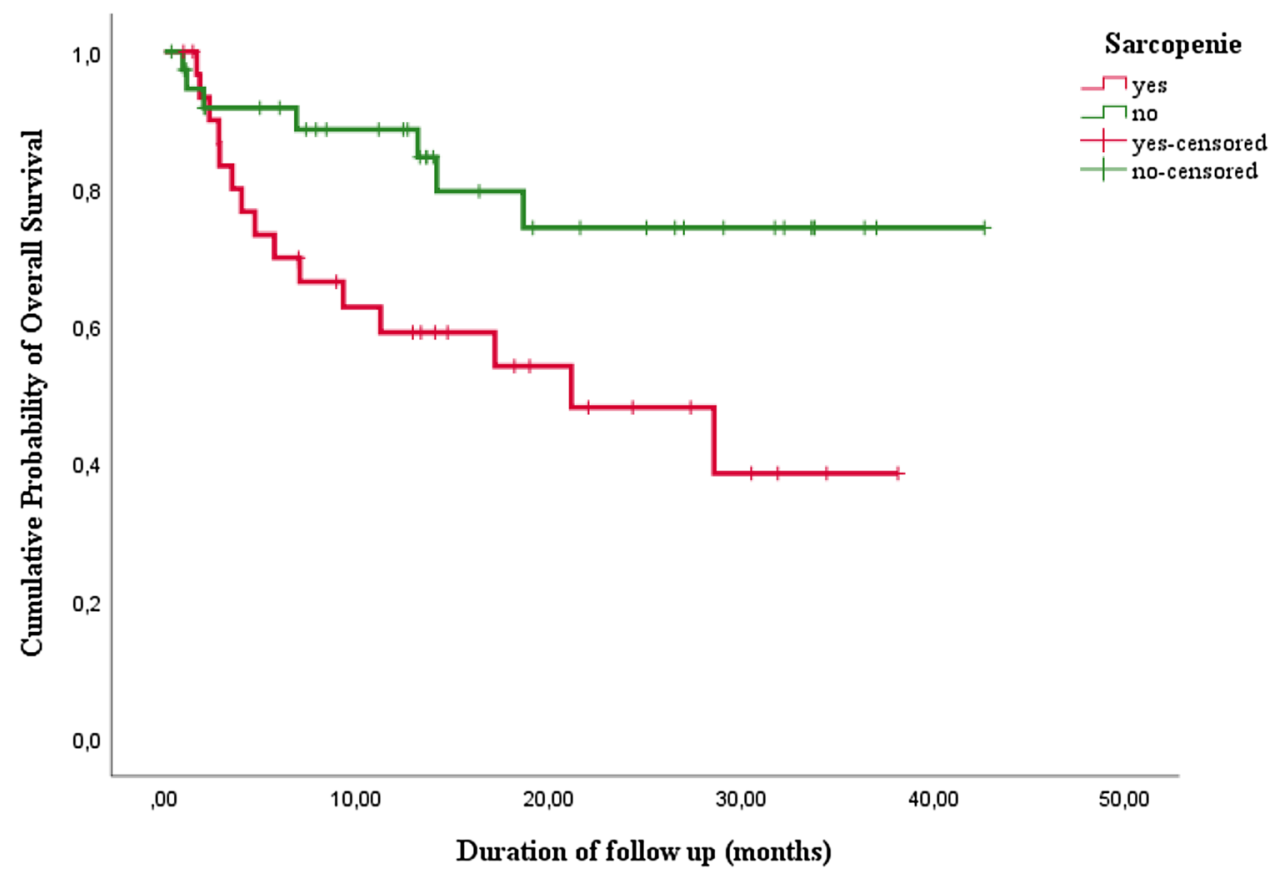

\begin{tabular}{|l|l|l|l|l|}
\hline & $T=0$ & $T=12$ & $T=24$ & $T=36$ \\
\hline Sarcopenia & 32 & 16 & 7 & 1 \\
\hline Without sarcopenia & 39 & 24 & 12 & 3 \\
\hline
\end{tabular}

than a combination of low SMM and low MF [25-28]. Our study highlights the importance of defining sarcopenia as a combination of SMM and MF.

In multivariate analysis including the covariates age, Hb level, MUST score, BMI, and comorbidity; sarcopenia remained a statistically significant prognostic factor for overall survival. When including TNM stage in the multivariate analysis, sarcopenia did not remain a statistically significant prognostic factor for overall survival. Subgroup analyses according to TNM stage and treatment intention shows that sarcopenia is a statistically significant prognostic factor for overall survival in patients with TNM stage I-III and in all patients with curative treatment intention. In patients with TNM stage IV, sarcopenia is not a statistically significant prognostic factor for overall survival. In this study, 39 patients $(45.9 \%)$ had a TNM stage IV; it is possible that sarcopenia did not remain a significant prognostic factor in model 2 of the multivariate analysis because of the high number of patients with TNM stage IV. This finding is in accordance with a previous study performed in patients with gastric cancer which showed that sarcopenia is a significant prognostic factor for overall survival in patients with TNM stage II-III [30]. It is also in accordance with a recent systematic review, which showed that sarcopenia is a significant prognostic factor for overall survival in different types of cancers independent of TNM stage [29].

The existing literature on sarcopenia in patients with head-and-neck cancer is scarce and focuses mainly on low SMM in patients who receive (chemo)radiotherapy [7] or patients who undergo a total laryngectomy [10, 11]. To our knowledge, our study is the first to investigate the impact of sarcopenia, defined as a combination of SMM and MF, in elderly ( $\geq 70$-years old) head-and-neck cancer patients.

This study has some limitations. It was designed as a retrospective single-center study, which increases the risk for systemic errors. It had limited number of included patients which may have led to type II errors. Only patients with the available data on SMM and MF were included in the study. As it is more likely that MF parameters were examined for frail patients than for fit patients, this may have resulted in a biased study population in which it is probably more difficult to show the prognostic value of sarcopenia. Therefore, sarcopenia a combination of SMM and MF should be further evaluated as a prognostic factor for overall survival in elderly patients with head-and-neck cancer. 
Table 5 Univariate and multivariate analyses of the hazard ratios for sarcopenia, age, $\mathrm{Hb}$ level, BMI, MUST score, CCI, and TNM stage as independent prognostic factors for overall survival

\begin{tabular}{|c|c|c|c|c|c|c|c|c|c|}
\hline \multirow[t]{4}{*}{ Variable } & \multicolumn{9}{|c|}{ Overall survival } \\
\hline & \multirow{2}{*}{\multicolumn{3}{|c|}{ Univariate analysis }} & \multicolumn{6}{|c|}{ Multivariate analysis $(*)$} \\
\hline & & & & \multicolumn{3}{|c|}{ Model 1} & \multicolumn{3}{|c|}{ Model 2} \\
\hline & HR & $95 \% \mathrm{CI}$ & $p$ value & HR & $95 \% \mathrm{CI}$ & $p$ value & HR & $95 \% \mathrm{CI}$ & $p$ value \\
\hline Sarcopenia & 2.80 & $1.14-6.88$ & $0.03 *$ & 2.66 & $1.07-6.58$ & $0.04 *$ & 1.36 & $0.48-3.83$ & 0.56 \\
\hline Age (years) & 1.03 & $0.95-1.11$ & 0.48 & 1.02 & $0.94-1.11$ & 0.59 & 1.05 & $0.97-1.13$ & 0.26 \\
\hline $\mathrm{Hb}(\mathrm{mmol} / \mathrm{L})$ & 0.82 & $0.58-1.16$ & 0.26 & 0.90 & $0.61-1.32$ & 0.58 & & & \\
\hline \multicolumn{10}{|l|}{ BMI $\left(\mathrm{kg} / \mathrm{m}^{2}\right)$} \\
\hline$<18.5$ & - & - & - & - & - & - & - & - & - \\
\hline $18.5-25$ & Ref & & & Ref & & & Ref & & \\
\hline $25-30$ & 0.54 & $0.21-1.38$ & 0.20 & 0.54 & $0.21-1.39$ & 0.20 & 0.50 & $0.19-1.31$ & 0.16 \\
\hline$\geq 30$ & 0.34 & $0.10-1.20$ & 0.10 & 0.45 & $0.12-1.64$ & 0.23 & 0.70 & $0.18-2.72$ & 0.61 \\
\hline \multicolumn{10}{|l|}{ MUST score } \\
\hline$<2$ & Ref & & & Ref & & & & & \\
\hline$\geq 2$ & 1.75 & $0.68-4.53$ & 0.25 & 1.36 & $0.47-3.95$ & 0.57 & & & \\
\hline \multicolumn{10}{|l|}{$\mathrm{CCI}$} \\
\hline$<6$ & Ref & & & Ref & & & Ref & & \\
\hline$\geq 6$ & 1.22 & $0.52-2.86$ & 0.65 & 0.92 & $0.35-2.40$ & 0.86 & 1.47 & $0.58-3.74$ & 0.42 \\
\hline \multicolumn{10}{|l|}{ TNM stage } \\
\hline I & Ref & & & - & - & - & Ref & & \\
\hline II & 0.96 & $0.06-15.40$ & 0.98 & & & & 0.96 & $0.06-15.40$ & 0.98 \\
\hline III & 5.24 & $0.57-48.46$ & 0.14 & & & & 5.24 & $0.57-48.46$ & 0.14 \\
\hline IV & 15.64 & $1.99-122.88$ & $0.01 *$ & & & & 15.64 & $1.99-122.88$ & $0.01 *$ \\
\hline
\end{tabular}

*Correlation is significant at the 0.05 level (two-tailed)

(*)Model 1 includes the variables; sarcopenia, age, hb value, BMI, MUST score, and CCI. Model 2 includes the variables; sarcopenia, age, BMI, CCI, and TNM stage
Concerning the imaging techniques used to assess SMM, we decided to include both CT scans and MRI scans of the head and neck area to assess SMM, to maximize the number of patients that could be included. Whenever available, we used CT imaging instead of MRI, because most research on SMM in cancer patients is performed using CT imaging. However, the CT measurement method for SMM was formulated on MRI-based research [30, 31].

Table 6 Subgroup analyses according to TNM stage and sarcopenia showed sarcopenia as a statistically significant prognostic factor for overall survival in all patients with curative treatment intention (HR $2.80 ; 95 \%$ CI $1.14-6.88 ; p=0.03)$ and in all patients with TNM stage I-III (HR 9.19; 95\% CI 1.07-78.74; $p=0.04$ )

\begin{tabular}{lllll}
\hline Subgroup & \multicolumn{4}{l}{ Overall survival } \\
\cline { 2 - 5 } & \multicolumn{2}{l}{ Sarcopenia } \\
\cline { 2 - 5 } & Frequency & HR & $95 \%$ CI & $p$ value \\
\hline TNM stage I-III & 32 & 9.19 & $1.07-78.74$ & $0.04^{*}$ \\
TNM stage IV & 39 & 0.90 & $0.32-2.55$ & 0.85 \\
Curative treatment intention & 71 & 2.80 & $1.14-6.88$ & $0.03^{*}$ \\
\hline
\end{tabular}

*Correlation is significant at the 0.05 level (two-tailed)
Theoretically, there is no difference in SMM between CT imaging and MRI, as both methods are very accurate for SMM assessment. Therefore, we believe that it is acceptable to use MRI for the SMM measurement when CT imaging is not available. Research should be conducted to investigate this further.

In retrospective studies, data on MF will probably rarely be available, whereas CT or MRI is often routinely performed in head-and-neck cancer patients. We propose to conduct further prospective studies for the measurement of both MF and SMM and to perform routine handgrip strength measurements in every newly diagnosed head-and-neck cancer patient.

In conclusion, sarcopenia is present in half of the elderly HNSCC patients. Skeletal muscle mass index and muscle function, as determined by muscle strength or physical performance measurements, were not prognostic separately in elderly HNSCC patients, but the combination of both was prognostic for overall survival. Therefore, it may be preferable to define sarcopenia as the combination of low skeletal muscle mass and low muscle function and not by radiologically assessed skeletal muscle mass alone. 
Funding This research received a grant from the Michel Keijzer Fonds, a not for profit fund managed by the Dutch Head and Neck Cancer patient support group (PVHH).

\section{Compliance with ethical standards}

Conflict of interest The authors declare that they have no conflict of interest.

Ethical approval All procedures in this study were in accordance with the ethical standards of the institutional and/or national research committee and with the 1964 Helsinki declaration and its later amendments or comparable ethical standards

Informed consent A formal informed consent procedure was waived due to the retrospective nature of this study. The design of this study was approved by the Medical Ethical Research Committee of our center (approval ID 17-365).

Open Access This article is distributed under the terms of the Creative Commons Attribution 4.0 International License (http://creativeco mmons.org/licenses/by/4.0/), which permits unrestricted use, distribution, and reproduction in any medium, provided you give appropriate credit to the original author(s) and the source, provide a link to the Creative Commons license, and indicate if changes were made.

\section{References}

1. Cruz-Jentoft AJ, Baeyens JP, Bauer JM, Boirie Y, Cederholm T, Landi F, Martin FC, Michel JP, Rolland Y, Schneider SM, Topinkova E, Vandewoude M, Zamboni M (2010) Sarcopenia: European consensus on definition and diagnosis: report of the European Working Group on sarcopenia in older people. Age Ageing 39(4):412-423. https://doi.org/10.1093/ageing/afq034

2. von Haehling S, Morley JE, Anker SD (2010) An overview of sarcopenia: facts and numbers on prevalence and clinical impact. J Cachexia Sarcopenia Muscle 1(2):129-133. https://doi. org/10.1007/s13539-010-0014-2

3. Rolland Y, Van Kan G, Abellan, Gillete-Guyonnet S, Vellas B (2011) Cachexia versus sarcopenia. Curr Opin Clin Nutr Metab Care 14:15-21. https://doi.org/10.1097/MCO.0b013e328340c2c 2

4. Goodpaster BH, Park SW, Harris TB, Kritchevsky SB, Nevitt M, Schwartz AV, Simonsick EM, Tylavsky FA, Visser M, Newman AB (2006) The loss of skeletal muscle strength, mass, and quality in older adults: the health, aging and body composition study. J Gerontol Ser A Biol Sci Med Sci 61(10):1059-64. (PMID: 17077199)

5. Janssen I, Baumgartner RN, Ross R, Rosenberg IH, Roubenoff R (2004) Skeletal muscle cutpoints associated with elevated physical disability risk in older men and women. Am J Epidemiol 159(4):413-421. (PMID: 14769646)

6. Shachar SS, Williams GR, Muss HB, Nishijima TF (2016) Prognostic value of sarcopenia in adults with solid tumours: A metaanalysis and systematic review. Eur J Cancer 57:58-67. https:// doi.org/10.1016/j.ejca.2015.12.030

7. Wendrich AW, Swartz JE, Bril SI, Wegner I, de Graeff A, Smid EJ, de Bree R, Pothen AJ (2017 Aug) Low skeletal muscle mass is a predictive factor for chemotherapy dose-limiting toxicity in patients with locally advanced head and neck cancer. Oral Oncol 71:26-33. https://doi.org/10.1016/j.oraloncology.2017.05.012
8. Prado CM, Baracos VE, McCargar LJ, Reiman T, Mourtzakis M, Tonkin K, Mackey JR, Koski S, Pituskin E, Sawyer MB (2009) Sarcopenia as a determinant of chemotherapy toxicity and time to tumor progression in metastastic breast cancer patients receiving capecitabine treatment. Clin Cancer Res 15(8):2920-6. https:// doi.org/10.1158/1078-0432.CCR-08-2242

9. Antoun S, Baracos VE, Escudier B, Sawyer MB (2010) Low body mass index and sarcopenia associated with dose-limiting toxicity of sorafenib in patients with renal cell carcinoma. Ann Oncol 21:1594-1598. https://doi.org/10.1093/annonc/mdp605

10. Achim V, Bash J, Mowery A, Guimaraes AR, Li R, Schindler J, Wax M, Andersen P, Clayburgh D (2017) Prognostic indication of sarcopenia for wound complication after total laryngectomy. JAMA Otolaryngol Head Neck Surg 143(12):1159-1165. https ://doi.org/10.1001/jamaoto.2017.0547

11. Bril SI, Pezier TF, Tijink BM, Janssen LM, Braunius WW, de Bree R (2019) Preoperative low skeletal muscle mass as a risk factor for pharyngocutaneous fistula and decreased overall survival in patients undergoing total laryngectomy. Head Neck. https://doi. org/10.1002/hed.25638

12. Ida S, Watanabe M, Yoshida N, Baba Y, Umezaki N, Harada K, Karashima R, Imamura Y, Iwagami S, Baba H (2015) Sarcopenia is a predictor of postoperative respiratory complications in patients with esophageal cancer. Ann Surg Oncol 22(13):44324437. https://doi.org/10.1245/s10434-015-4559-3

13. van Vugt JL, Braam HJ, van Oudheusden TR, Vestering A, Bollen TL, Wiezer MJ, de Hingh IH, van Ramshorst B, Boerma D (2015) Skeletal muscle depletion is associated with severe postoperative complications in patients undergoing cytoreductive surgery with hyperthermic intraperitoneal chemotherapy for peritoneal carcinomatosis of colorectal cancer. Ann Surg Oncol 22(11):3625-3631. https://doi.org/10.1245/s10434-015-4429-z

14. Nishikawa D, Hanai N, Suzuki H, Koide Y, Beppu S, Hasegawa Y (2018) The impact of skeletal muscle depletion on head and neck squamous cell carcinoma. ORL J Otorhinolaryngol Relat Spec 80:1-9. https://doi.org/10.1159/000485515

15. Miyamoto Y, Baba Y, Sakamoto Y, Ohuchi M, Tokunaga R, Kurashige J, Hiyoshi Y, Iwagami S, Yoshida N, Yoshida M, Watanabe M, Baba H (2015) Sarcopenia is a negative prognostic factor after curative resection of colorectal cancer. Ann Surg Oncol 22:2663-2668. https://doi.org/10.1245/s10434-014-4281-6

16. Okumura S, Kaido T, Hamaguchi Y, Fujimoto Y, Masui T, Mizumoto M, Hammad A, Mori A, Takaori K, Uemoto S (2015) Impact of preoperative quality as well as quantity of skeletal muscle on survival after resection of pancreatic cancer. Surgery 157(6):1088-1098. https://doi.org/10.1016/j.surg.2015.02.002

17. Fukuda Y, Yamamoto K, Hirao M et al (2016) Sarcopenia is associated with severe postoperative complications in elderly gastric patients undergoing gastrectomy. Gastric Cancer 19(3):986-993. https://doi.org/10.1007/s10120-015-0546-4

18. Heymsfield SB, Wang Z, Baumgartner RN, Ross R (1997) Human body composition: advances in models and methods. Annu Rev Nutr 17:527-558

19. Swartz JE, Pothen AJ, Wegner I, Smid EJ, Swart KM, de Bree R, Leenen LP, Grolman W (2016) Feasibility of using head and neck CT imaging to assess skeletal muscle mass in head and neck cancer patients. Oral Oncol 62:28-33. https://doi.org/10.1016/j. oraloncology.2016.09.006

20. Lauretani F, Russo CR, Bandinelli S, Cavazzini C, Di lorio A Corsi AM, Rantanen T, Guralnik JM, Ferrucci L (2003) Age-associated changes in skeletal muscles and their effect on mobility: an operational diagnosis of sarcopenia. J Appl Physiol 95(5):18511860. https://doi.org/10.1152/japplphysiol.00246.2003

21. Studenski S, Perera S, Wallace D, Chandler JM, Duncan PW, Rooney E, Fox M, Guralnik JM (2003) Physical performance 
measures in the clinical setting. J Am Geriatr Soc 51(3): 314-322. (PMID: 12588574)

22. Morishita S (2016) Prevalence of sarcopenia in cancer patients: review and future directions. Int J Phys Med Rehabil 4:3. https:// doi.org/10.4172/2329-9096.1000342

23. Hairi NN, Cumming RG, Naganathan V, Handelsman DJ, Le Couteur DG, Creasey H, Waite LM, Seibel MJ, Sambrook PN. Loss of muscle strength, mass (sarcopenia), and quality (specific force) and its relationship with functional limitation and physical disability: the concord health and ageing in men project. J Am Geriatr Soc 58 (11):2055-62. https://doi.org/10.111 1/j.1532-5415.2010.03145.x

24. Zoico E, Di Francesco V, Guralnik J, Mazzali G, Bortolani A, Guariento S, Sergi G, Bosello O, Zamboni M (2004) Physical disability and muscular strength in relation to obesity and different body composition indexes in a sample of healthy elderly women. Int J Obes Relat Metab Disord 28(2):234-241. https:// doi.org/10.1038/sj.ijo.0802552

25. Grotenhuis BA, Shapiro J, van Adrichem S, de Vries M, Koek M, Wijnhoven BPL, van Lanschot J (2016) Sarcopenia/muscle mass is not a prognostic factor for short- and long-term outcome after esophagectomy for cancer. World J Surg 40(11):2698-2704. https ://doi.org/10.1007/s00268-016-3603-1

26. Awad S, Tan BH, Cui H, Bhalla A, Fearon KC, Pearsons SL, Catton JA, Lobo DN (2012) Marked changes in body composition following neoadjuvant chemotherapy for oesophagogastric cancer. Clin Nutr 31:74-77. https://doi.org/10.1016/j.clnu.2011.08.008

27. Yip C, Goh V, Davies A, Gossage J, Mitchell-Hay R, Hynes O, Maisey N, Ross P, Gaya A, Landau DB, Cook GJ, Griffin N, Mason R (2014) Assessment of sarcopenia and changes in body composition after neoadjuvant chemotherapy and associations with clinical outcomes in oesophageal cancer. Eur Radiol 24:9981005. https://doi.org/10.1007/s00330-014-3110-4

28. Sheetz KH, Zhao L, Holcombe SA, Wang SC, Reddt RM, Lin J, Orringer MB, Chang AC (2013) Decreased core muscle size is associated with worse patient survival following esophagectomy for cancer. Dis Esophagus 26:716-722. https://doi.org/10.1111/ dote. 12020

29. Pamoukdjian F, Bouillet T, Levy V, Soussan M, Zelek L, Paillaud E (2018) Prevalence and predictive value of pre-therapeutic sarcopenia in cancer patients: a systematic review. Clin Nutr 37(4):1101-1113. https://doi.org/10.1016/j.clnu.2017.07.010

30. Zhuang CL, Huang DD, Pang WY, Zhou CJ, Wang SL, Lou N, Ma LL, Yu Z, Shen X (2016) Sarcopenia is an independent predictor of severe postoperative complications and long-term survival after radical gastrectomy for gastric cancer: analysis from a largescale cohort. Medicine 95(13):e3164. https://doi.org/10.1097/ MD.0000000000003164

31. Prado CM, Lieffers JR, McCargar LJ, Reiman T, Sawyer MB, Martin L et al (2008) Prevalence and clinical implications of sarcopenic obesity in patients with solid tumours of the respiratory and gastrointestinal tracts: a population-based study. Lancet Oncol 9(7):629-635. https://doi.org/10.1016/S1470-2045(08)70153-0

32. Shen W, Punyanitya M, Wang Z, Gallagher D, St-Onge MP, Albu $\mathrm{J}$ et al (2004) Total body skeletal muscle and adipose tissue volumes: estimation from a single abdominal cross-sectional image. J Appl Physiol (1985) 97(6):2333-2338. https://doi.org/10.1152/ japplphysiol.00744.2004

Publisher's Note Springer Nature remains neutral with regard to jurisdictional claims in published maps and institutional affiliations. 